\title{
Apprenticeship-based training in neurogastroenterology and motility
}

DOI:

10.1080/17474124.2018.1406308

\section{Document Version}

Accepted author manuscript

Link to publication record in Manchester Research Explorer

\section{Citation for published version (APA):}

Vasant, D., Sharma, A., Bhagatwala, J., Viswanathan, L., \& Rao, S. S. C. (2017). Apprenticeship-based training in neurogastroenterology and motility. Expert Review of gastroenterology and Hepatology, 1-8.

https://doi.org/10.1080/17474124.2018.1406308

\section{Published in:}

Expert Review of gastroenterology and Hepatology

\section{Citing this paper}

Please note that where the full-text provided on Manchester Research Explorer is the Author Accepted Manuscript or Proof version this may differ from the final Published version. If citing, it is advised that you check and use the publisher's definitive version.

\section{General rights}

Copyright and moral rights for the publications made accessible in the Research Explorer are retained by the authors and/or other copyright owners and it is a condition of accessing publications that users recognise and abide by the legal requirements associated with these rights.

\section{Takedown policy}

If you believe that this document breaches copyright please refer to the University of Manchester's Takedown Procedures [http://man.ac.uk/04Y6Bo] or contact uml.scholarlycommunications@manchester.ac.uk providing relevant details, so we can investigate your claim.

\section{OPEN ACCESS}




\section{Apprenticeship-based training in neurogastroenterology and motility}

\section{Dipesh H. Vasant, Amol Sharma, Jigar Bhagatwala, Lavanya Viswanathan \& Satish S.C. Rao}

To cite this article: Dipesh H. Vasant, Amol Sharma, Jigar Bhagatwala, Lavanya Viswanathan \& Satish S.C. Rao (2017): Apprenticeship-based training in neurogastroenterology and motility, Expert Review of Gastroenterology \& Hepatology, DOI: $\underline{10.1080 / 17474124.2018 .1406308}$

To link to this article: http://dx.doi.org/10.1080/17474124.2018.1406308

Accepted author version posted online: 15

Nov 2017.

Submit your article to this journal $\llbracket$

Q View related articles $₫$

View Crossmark data \ulcorner 
Publisher: Taylor \& Francis

Journal: Expert Review of Gastroenterology \& Hepatology

DOI: $10.1080 / 17474124.2018 .1406308$

\section{Review}

\section{Apprenticeship-based training in neurogastroenterology and motility}

Dipesh H. Vasant ${ }^{1,2}$, Amol Sharma ${ }^{1}$, Jigar Bhagatwala ${ }^{1}$, Lavanya Viswanathan ${ }^{1}$ and Satish S.C. Rao ${ }^{1}$

${ }^{1}$ Division of Gastroenterology and Hepatology, Digestive Health Center, Augusta University, Medical College of Georgia, Augusta, Georgia, USA

${ }^{2}$ Division of Diabetes, Endocrinology \& Gastroenterology, Manchester Academic Health Sciences Centre, University of Manchester, Manchester, United Kingdom

\section{Correspondence:}

Satish S.C. Rao

$112015^{\text {th }}$ Street, AD2226, Augusta University, Augusta, GA, 30912, USA

Office: +1-706-721-2238

Fax: +1-706-721-0331

E-mail: srao@augusta.edu 


\section{Abstract}

Introduction: Although neurogastroenterology and motility (NGM) disorders affect $50 \%$ of patients seen in clinics, many gastroenterologists receive limited NGM training. One-month apprenticeship-based NGM training has been provided at ten centers in the USA for a decade, however, outcomes of this training are unclear. Our goal was to describe the effectiveness of this program from a trainees perspective.

Areas Covered: We describe the training model, learning experiences, and outcomes of one-month apprenticeship-based training in NGM at a center of excellence, using a detailed individual observer account and data from 12 consecutive trainees that completed the program. During a one-month training period, 302 procedures including; breath tests $(B T) n=132$, anorectal manometry $(A R M) n=29$ and esophageal manometry $(E M) n=28$, were performed. Post-training, all trainees $(n=12)$ knew indications for motility tests, and the majority achieved independence in basic interpretation of BT, EM and ARM. Additionally, in a multiplechoice NGM written-test paper, trainees achieved significant improvements in test scores post-training $(\mathrm{P}=0.003)$.

Expert Commentary: One-month training at a high-volume center can facilitate rapid learning of NGM and the indications, basic interpretation and utility of motility tests. Trainees demonstrate significant independence, and this training model provides an ideal platform for those interested in sub-specialty NGM.

Keywords: Competency, Curriculum, Education, Neurogastroenterology, Motility, Training 


\section{Introduction:}

Neurogastroenterology and motility (NGM) disorders account for almost one half of the patients seen by gastroenterologists $[1,2,3]$. Despite this, most gastroenterologists are not adequately trained in the evaluation and management of these disorders $[4,5,6]$. Recent surveys in the UK have highlighted this problem and the need to improve training $[7,8,9]$. In the USA, a defined curriculum outlines the standards for basic and advanced training in gastrointestinal motility[10]. Many programs now offer some training, although very few centers offer comprehensive and/or 'hands-on' motility training[11]. In order to enhance NGM training, the American Neurogastroenterology and Motility Society (ANMS) designated ten 'centres of excellence'. These centres have offered one-month apprenticeship-based clinical training programs and broad-range exposure to motility disorders for the last decade[6].

In this paper, we detail the specifics of the training model at an ANMS center of excellence, illustrate the individual account of an observer during a typical month of apprenticeship-based training. We also provide a summary of the outcomes reported by twelve trainees and their experiences over the past few years from this training program. Additionally, we discuss how such NGM training could be implemented at centers world-wide.

\section{Materials and Methods:}

\subsection{The learning environment:}

Located in southeastern United States, Augusta University's Medical College of Georgia was founded in 1828 and is the thirteenth oldest medical school in the country. In spring 2015, a unique, single-site, multidisciplinary, 43,000 square feet, purpose-built Digestive Health Center (DHC) opened. Within the DHC, the motility clinic is the largest and most advanced of its kind in the United States and is one of ten ANMS centers of excellence[12]. The motility laboratory performs over 3,200 motility procedures annually, encompassing 18 different motility tests.

\subsection{NGM facilities and training resources}


The NGM lab consists of five dedicated rooms. This includes a 300 square feet room with two beds for upper GI motility, two separate rooms for lower GI motility with attached bathrooms (one for diagnostic and one for therapeutic procedures) and two Breath Testing rooms. There is also a motility fellow/ trainees office, situated along the same corridor. This dedicated workspace with a computer and up-to-date software provides the facilities for the motility trainee to read, interpret, and report motility studies. It also serves as devoted space for data interpretation rounds with faculty mentors. The motility outpatient clinics with 15 consultation rooms occur on the same floor in close proximity to the nine-room endoscopy unit and motility lab. Trainees were provided with a reading list and access to a library of motility textbooks, handbooks and relevant literature.

\subsection{The trainers and the team}

The motility team led by two physicians (SSCR/AS) also includes a nurse practitioner, motility fellows, a specialist dietician, two motility nurses, a nursing assistant and a post doctoral research fellow.

\subsection{Observations from an NGM 'center of excellence':}

To quantify and describe the learning experience during a typical month of apprenticeship-based training, a trainee (DHV) spent one-month at an ANMS 'center of excellence' shadowing two mentors. The trainee kept a log of all motility procedures and NGM clinic encounters that he was actively involved with during the training program, in order to facilitate the assessment of knowledge and competence at the end of the rotation. The visiting trainee was expected to make independent interpretations of motility procedures that were verified and validated by the mentors for accuracy and completeness.

The trainee's NGM competency during a typical month of laboratory and clinical activity was systematically documented and critically appraised. A formal face-toface evaluation at the end of training consisted of an observed assessment of the interpretation of motility data on a random selection of breath tests, esophageal manometry, anorectal manometry and wireless motility capsule studies by two faculty members. 


\subsection{Training outcomes}

1. In order to evaluate the outcomes following one-month of apprenticeshipbased training at a single center, post-training evaluation forms that were prospectively collected and were provided to us by the ANMS as anonymous data for the purposes of this article. Data captured from these questionnaires included whether the program fulfilled learning objectives, trainee level of independence in the indications, interpretation, and performance of motility tests at the end of the one-month apprentice-based program, trainee opinions on the optimal duration of the program, overall rating and the trainees' opinions on GI motility, their career aspirations and the amount of time that should be dedicated to this field during training.

2. As a quantitative measure of clinical knowledge, data interpretation skills, and clinical application, the ANMS devised a 60-item written NGM exam. This exam derived from the ANMS syllabus for the training program was undertaken by all trainees pre and post training. Mean test scores were compared before and after apprenticeship-based training for all trainees.

\subsection{Data Analysis:}

Data were analyzed using a Microsoft excel spreadsheet. Pre and post-training exam test scores were compared statistically using paired t-tests on a standard software statistics package (Stats Direct v3.0, Cheshire, UK),

\section{Results:}

\subsection{NGM Clinical Training Program (one-month):}

The NGM clinical training program consisted of didactic lectures on 16 motility topics which have been developed nationally by the ANMS course directors. Trainees also participated in outpatient clinics, observation of the performance of 18 different motility procedures, both in the laboratory and during endoscopy, occasional inpatient consultations and participation in daily motility data interpretation rounds. Table 1 shows the weekly timetable at this center. 


\subsection{NGM teaching clinics:}

Trainees participated in the comprehensive evaluation of patients with motility disorders in tertiary NGM outpatient clinics. Half-day motility clinics were set up as 'teaching clinics' twice weekly. These specialized clinics included out-of state patients, tertiary referrals and patients with complex functional and gastrointestinal motility problems. Trainees and nurse practitioners would become skilled in assimilating patient information, taking focussed histories and performing examinations, making differential diagnoses and management plans before presenting all cases to the attending physician at the bedside who would then revisit all the important components of the history, perform a detailed evaluation including physical examination and explained the rationale for the agreed management and investigation plan to the trainees/nurse practitioner and to the patient. The visiting trainee attended seven such clinics during the one-month period and observed the management of ninety clinic patients with a variety of complex NGM problems (Table 2). Several patients who were referred from out of state spent a whole week undergoing a series of tests and providing a comprehensive assessment of their underlying problem(s) and a care management plan.

\subsection{Training in the motility laboratory:}

Week 1: During the first week, the observer trainee (DHV) and three first year Gastroenterology fellows attended a tutorial with the motility faculty (SSCR/AS). The topics covered during this session included an introduction to high resolution esophageal and anorectal manometry including how to use the software, esophageal $\mathrm{pH}$ studies, hydrogen-methane breath tests and wireless motility capsule studies, with a case-based interactive approach. Trainees were taught the principles of interpretation of these different types of studies by working through cases with the faculty. Trainees made themselves familiar with the motility laboratory and indications for various tests, learnt how to use the equipment and computer software and were taught how to perform various motility tests, including how to calibrate, set up equipment and interpret these tests. Trainees were also encouraged to place probes and actively participate in the performance of studies.

Weeks 2-4: Experience was gained in high resolution esophageal impedance manometry, 24-hour ambulatory impedance $\mathrm{pH}$ study, hydrogen-methane breath 
tests (Glucose, Lactose, Fructose and Fructan), high-resolution and high-definition anorectal manometry, biofeedback therapy, wireless motility capsule test, gastric emptying and colonic transit tests. Additionally, there was exposure to advanced procedures including impedance planimetry, functional luminal impedance planimetry (EndoFLIP), gastric barostat study, antroduodenal manometry, colonic manometry, rectal barostat study, and gut-brain-gut neurophysiological studies.

All motility studies conducted in the laboratory were independently reviewed and interpreted by the visiting trainee (DHV) and by the motility fellow (JB/LV). Trainee reports were in turn reviewed by faculty mentors. Interesting findings were discussed and provisional reports were compared for learning purposes, before being finalised by the faculty members (SSCR/AS) who often provided feedback on the trainee's interpretation at the end of the day. During the one month attachment the observer trainee and motility fellow were involved with reporting 302 motility procedures. During the month, the most commonly performed procedures were hydrogenmethane breath tests, biofeedback therapy, anorectal manometry and esophageal manometry (Figure 1).

\subsection{Observations from NGM training in endoscopy:}

During weekly motility endoscopy lists, there were also opportunities for trainees to assist where possible in endoscopic interventions on patients with motility disorders, for example in botox injections, obtaining aspirates for small intestinal bacterial cultures, achalasia balloon dilatations, placement of colonic and small bowel manometry catheters, wireless (Bravo) pH capsule and feeding tube placements.

\subsection{Other learning opportunities during one-month apprenticeship-based training:}

During NGM clinical training, motility trainees also participated and presented cases at the dysphagia conference and the bi-monthly pelvic floor conference. Motivated trainees were also given opportunities to participate in clinical research projects in the motility unit and were invited to attend weekly research team meetings. The observer trainee took the opportunity to conduct a clinical research project examining the clinical utility of high definition (3D) anorectal manometry in the evaluation of pelvic floor disorders and its comparative utility with high resolution anorectal manometry. Along with a post-doctoral Fellow, the trainee served as an independent 
interpreter of the data and wrote-up the findings as abstracts that were submitted for an international meeting $[13,14]$. This work was presented at Digestive Disease Week in 2017.

\subsection{Training outcomes from apprenticeship-based NGM training}

Feedback forms from previous trainees $(n=12)$ from institutions all over the United

States that completed the program at this center were analyzed. The majority $(8 / 12$ trainees) were year 3 fellows, 11/12 were interested in a career in GI motility and $12 / 12$ confirmed they would be performing GI motility procedures in their future practice. All twelve trainees learning objectives were fulfilled at the end of the program, all twelve confirmed they would 'definitely' recommend this program to another colleague or fellow and 6/12 (50\%) rated their experience with the program as 'outstanding', 5/12 (42\%) rated it 'excellent' and 1 trainee rated the program as 'very good'. Trainees' responses regarding their level of independence in the indications, interpretation and performance of motility studies after the program are summarized in Figures 2-4. The majority of trainees (10/12, 83\%) felt that the onemonth duration of the program was 'adequate', whereas two participants recommended extending the program to two-months. Given the choice, most trainees $(9 / 12,75 \%)$ feel that 3 months of the Gl fellowship should be devoted to motility, whereas only one trainee suggested 2 months, another suggested 4 months and one suggested 6 months.

Qualitative feedback from several trainees suggested the provision of a library of motility studies with self-assessment answers would be beneficial.

\subsection{Comparison of written test scores before and after training}

All trainees that completed the program at this test center had a mean test score of $39 / 60(65 \%)$ at baseline which significantly improved at the end of training (45/60, $75 \%$ ), $95 \% \mathrm{Cl}=-9.47144$ to $-2.750782, \mathrm{t}=-4.2, \mathrm{P}=0.003$ (Figure 5).

\section{Discussion:}

During a typical month of outpatient and laboratory activity at a high-volume ANMS center of excellence, the visiting trainee was exposed to a wide variety of complex cases, novel technologies, over three hundred motility procedures. When the 
trainee's exposure to NGM procedures were compared to outcomes and experiences of previous trainees, it was notable that the procedures that were most frequently encountered (breath tests, high resolution anorectal manometry and high resolution esophageal manometry) were amongst those that trainees felt most comfortable to practice independently at the end of the program.

The data presented here suggest that after a one-month apprenticeship-based program at a high-volume center working with expert NGM sub-specialist clinicians, gastroenterology trainees have a good working knowledge of the indications, learn the basic skills on how to interpret a variety of motility investigations, and gain a comprehensive approach towards evaluating patients with NGM problems. Most trainees $(9 / 12,75 \%)$ who completed one-month apprenticeship training at this particular NGM training center went on to pursue academic medicine as directors of motility at various teaching institutions across the USA and Canada. By contrast, previously published post-program evaluation data from 90 trainees (data obtained from all ANMS training centers nationally) from trainees that have completed the one-month ANMS training program, suggest that around a third of trainees pursued academic medicine [6].

Most of the trainees in the present study agreed that the one-month duration of this program is 'adequate', the post-program evaluation data suggest that it is not possible to achieve independence in performing more complex procedures such as antroduodenal manometry and biofeedback therapy within this timeframe. Trainees view this program as an adjunct to motility training within post-doctoral fellowship training and the majority suggested that at least 3 months of Gastroenterology fellowship should be dedicated to learning NGM.

In addition to the educational outcomes of the program, motivated trainees were given opportunities to undertake relevant clinically orientated research projects during the month which led to a presentation at an international conference [13], further attesting to the plausibility of a comprehensive clinical training that can be achieved through a dedicated one-month apprenticeship-based program.

One of the limitations of our study include the lack of baseline data collected from previous trainees on their exposure to NGM training during their fellowship and their baseline level of competency prior to the program. It is therefore difficult to determine 
whether the level of independence achieved at the completion can be solely attributed to the program itself. However, both the positive feedback from trainees and the improved performance in the ANMS written test before and after training suggests that the program itself strongly influenced the outcomes. Moreover, the observed trend toward a higher level of 'independence' in motility procedures, was observed in the procedures most commonly performed, again suggesting that this exposure during the month of training was important in achieving the observed positive outcomes. Whilst all trainees at this center received training in wireless motility capsule ( $n=16$ procedures during a typical month), data for independence with this technique was not obtained due to use of an old feedback form which predated the advent of this test.

Another limitation to our study is responder bias. The proportion of trainees at this ANMS center of excellence were highly motivated and interested in the subspecialty with all but one with future plans on pursuing a career in NGM. All indicated their intent to perform GI motility procedures in their future practice. This may not be the makeup of trainees during the one-month apprenticeship program at other ANMS centers of excellence, which may partially account for the observed higher numbers of trainees pursuing academic medicine from this training center compared to the numbers reported by trainees from other ANMS training centers nationally [6].

One of the key questions that emerges from our study is how best to assess competency progression in NGM training. The curriculum-based ANMS exam is one way of testing baseline knowledge and interpretation skills and whilst the improvement in test scores may be a reflection of learning, the use of the same test at the end, even after concealing the answers, may have led to some trainees learning the correct answers rather than the application of newly acquired knowledge. Another assessment method was the end of program face-to-face assessment of trainee interpretation of motility data with faculty members which had clear educational benefits, particularly in terms of verbal feedback. This is probably one of the best methods currently available. However, even this method of evaluation is susceptible to variability in the difficulty of the cases encountered during the one-month apprenticeship and subject to discrepancies in evaluation amongst faculty. Finally, the current standards defined by the core GI training curriculum to achieve expertise in NGM (level 2 training) are based upon achieving set numbers of 
procedures [10]. Based upon these recommendations and the number of procedures observed during a typical month of apprenticeship-based training (Figure 1), achieving level 2 standards in anorectal manometry $(n=30)$, biofeedback therapy $(n=10)$, esophageal $\mathrm{pH}$ metry $(n=25)$ would take just over a month of apprenticeshipbased training, whereas level 2 standards in esophageal manometry $(n=50)$ would take approximately two months of apprenticeship-based training to achieve and antroduodenal manometry $(n=25)$ would take even longer [10]. However, antroduodenal manometry is not offered at all centers of excellence and its clinical utility remains controversial. A combination of the above approaches described above may be the best available at present. Competency-based medical education in NGM is critical. Recent developments in this field and their relevance to the issues discussed here are covered in more depth in the commentary.

In summary, observations from an ANMS center of excellence in United States suggest that one-month apprenticeship-based training program at a high-volume center can facilitate rapid learning of the indications, interpretation and utility of the most commonly performed motility tests and appears to provide an ideal platform for all gastroenterology trainees. The optimal duration of NGM training remains unclear and whilst better methods of assessing competency progression in NGM are currently being developed, our data support that a further, extended period of training is required in order to sub-specialize in the full-range of NGM diagnostics and therapeutics.

\section{Expert Commentary:}

The need for 'special training modules' and development of NGM as a sub-specialty was identified a decade ago [6, 24, 25]. Unfortunately, training in NGM has largely been overshadowed by other competing areas of the gastroenterology curriculum including; endoscopy[6], hepatology, inflammatory bowel disease and nutrition, for which advanced training modules are now available in most countries.

However, the need for NGM specialist knowledge and training is increasing. Over the past decade there have been significant advances in NGM diagnostic testing and understanding of disease mechanisms, which have led to new disease classifications and therapies. Here, we discuss the implications of the advances in this field in terms of meeting increasing clinical demands, the requirement for $\mathrm{GI}$ 
curricula to keep up with the new developments in this field and review emerging concepts in motility training.

The one-month apprenticeship based model which is described in this article is an attractive approach to delivering NGM training. Whilst a one-month NGM rotation during training may not equate to competence as an advanced NGM clinician, it is likely to help produce a more well-rounded gastroenterologist, and given the short duration, is unlikely to detract from other competing sub-specialty areas of the curriculum. Moreover we would argue that such training is important because all gastroenterologists frequently encounter patients with NGM disorders.

Recent surveys support our conclusions by highlighting the consequences of deficiencies in NGM training, whereby a majority of GI clinicians in UK are unable to independently interpret motility studies, and often struggle to provide therapeutic recommendations $[7,8,9,15]$. Consequently, there is little doubt that training in NGM would be invaluable for all GI trainees, as well as improve the quality of patient care.

The UK data is particularly interesting given that ninety-eight GI physiology units have been identified as centers that perform GI motility procedures [8], suggesting a lack of training despite good availability of potential training centers. This almost certainly is a reflection of the absence of minimum standards in NGM related procedures and motility data interpretation in the UK gastroenterology curriculum. We can infer from this data that delivery of core training (such as during one month rotations), not only requires a dedicated team that perform a minimum number of upper and lower GI procedures, but also, NGM training requires formal recognition by the national training bodies as a core mandatory requirement, with clearly defined minimum standards.

Recently some efforts have been made to address these training deficiencies in the UK by raising awareness at the Association of Gastrointestinal Physiologists annual BSG symposium, the BSG trainees section who have included 'manometry: a fool's guide' in a trainees education weekend, and the NGM section committee who have since hosted a weekend workshop to cover these topics. Internationally, the European Society of Neurogastroenterology and motility (ESNM) have also recently held a successful three-day 'hands-on' motility course for twenty selected trainees. 
Whilst raising awareness via these educational forums will undoubtedly improve exposure, given the complexity of motility disorders and the technological advances and the steep learning curves for achieving competency in interpretation of motility procedures, similar to endoscopy training $[15,16,17,18,19]$, a dedicated training program is essential.

Competency based medical education is currently a hot topic in gastroenterology and more recently, an emerging concept in NGM. Indeed recent studies have suggested that competency-based training in motility should not be purely based on the number of procedures or the amount of time spent in training, but based on objective measures of performance $[16,17,18,19,20,21,22]$. With this in mind, Yadlapati et al. recently developed and piloted a high resolution esophageal manometry 'interpretation exam' with eight interpretation skills per case and suggest that this computer-based assessment tool could be applied in clinical practice to judge competency of trainees [22]. This competency-based approach appears promising and is likely to be available to be used in conjunction with workplace based assessments including direct observed procedural assessments (DOPs) [15].

The steep learning curve in high resolution manometry interpretation has recently been studied in trainees $[18,21]$. This was also experienced first-hand by the observer trainee, who under the mentorship of the experienced faculty members and senior trainees at the host institution, learnt how and when to override some of the automated analyses, and how slight adjustments in the measurement points on highresolution pressure topographies improved the diagnostic accuracy of the final interpretation and report. Regrettably, the UK national survey has however, suggested an over-reliance on computer generated and technical reports, often without interpretation by a trained sub-specialist clinician [8]. Recent publications have shown that this approach could potentially run the risk of variable standards, misinterpretation, incorrect diagnoses, and the need to repeat tests $[16,17,18,19$, 23].

A concerted effort is required by the NGM sections of various European GI societies and the ESNM to facilitate such training. This should include mandatory core standards in GI motility training within curricula and to learn from a decade of experience from USA. Once core and advanced curriculum standards have been 
defined, high-volume tertiary centers could be developed as 'centers of excellence' in NGM in their respective countries.

\section{Five-year view:}

Over the next five years, the need for specialist NGM knowledge, technical skills and ability to interpret complex data is likely to increase further and it is important that coverage during GI training reflects this worldwide. Delivery of this training will require inclusion of NGM in core curricula and dedicated NGM attachments. Implementation of novel, web-based competency assessment tools will complement apprenticeship-based training in NGM during short attachments and ensure that measureable standards are met at the end of the programme. Competency assessment tools could be developed for several different types of motility procedures to document trainees' learning curves, complement procedure logs and would be a step towards a much needed, robust certification pathway, for both core and advanced level training in NGM.

\section{Key Issues:}

- Recent studies have identified limited training opportunities in neurogastroenterology and motility, particularly in the UK, where there are currently no minimum standards for motility procedures in the curriculum.

- Exposure to intensive, one-month, apprenticeship-based training in neurogastroenterology and motility at a center of excellence develops core skills in comprehensively evaluating and managing complex gastrointestinal motility disorders.

- Similar training models in the UK and elsewhere internationally could significantly enhance learning, improve gastroenterology training, and fulfil the unmet gaps in the training curriculum. 


\section{Acknowledgements}

The authors would like to thank Mrs Helen Smith who provided excellent secretarial support and Lori Ennis from the American Society of Neurogastroenterology and Motility. This project would not have been possible without the support of Dr. Philip L Shields (Gastroenterology Training Programme Director, North West Deanery), Dr. Abhishek Sharma (Educational Supervisor, Lancashire Teaching Hospitals) and the mentorship of Professor Shaheen Hamdy (University of Manchester) and Dr Nerukav Radhakrishnan (Pennine Acute Hospitals NHS Trust).

\section{Funding}

This paper was supported by a fellowship grant from Shire Pharmaceuticals.

\section{Declaration of interest}

D. Vasant was the recipient of the 2016 Out Of Programme Prize Award by the British Society of Gastroenterology Trainees Section and a Visiting Fellowship Grant from Shire Pharmaceuticals. The authors have no other relevant affiliations or financial involvement with any organization or entity with a financial interest in or financial conflict with the subject matter or materials discussed in the manuscript apart from those disclosed. 


\section{References}

Papers of special note have been highlighted as:

* of interest

${ }^{* *}$ of considerable interest

1. Peery AF, Dellon ES, Lund J, Crockett SD, McGowan CE, Bulsiewicz WJ, Gangarosa LM, Thiny MT, Stizenberg K, Morgan DR, Ringel Y, Kim HP, Dibonaventura MD, Carroll CF, Allen JK, Cook SF, Sandler RS, Kappelman MD, Shaheen NJ. Burden of gastrointestinal disease in the United States: 2012 update. Gastroenterology. 2012;143:1179-87 e1-3. Epub 2012/08/14.

2. Camilleri M, Dubois D, Coulie B, Jones M, Kahrilas PJ, Rentz AM, Sonnenberg A, Stanghellini V, Stewart WF, Tack J. Prevalence and socioeconomic impact of upper gastrointestinal disorders in the United States: results of the US Upper Gastrointestinal Study. Clinical Gastroenterology and Hepatology. 2005;3:543-52.

3. Shivaji UN, Ford AC. Prevalence of functional gastrointestinal disorders among consecutive new patient referrals to a gastroenterology clinic. Frontline Gastroenterology. 2014.

4. Parkman HP. Training in gastrointestinal motility. Dig Dis. 2006;24:221-7. Epub 2006/07/20.

5. Parkman HP, Doma S. The importance of gastrointestinal motility disorders. Practical gastroenterology. 2006;30:23.

6. ${ }^{* *}$ Rao SS, Parkman HP. Advanced training in neurogastroenterology and gastrointestinal motility. Gastroenterology. 2015;148:881-5. Epub 2015/03/26.

** This key reference paper summarizes the background to the development of the one-month clinical training program in NGM in the USA.

7. Vasant D, Hamdy S, Solanki K, Senapati S, Smith L, Barlow J, Radhakrishnan N. OC-066 A National Survey of the Practice and Attitudes Towards Investigations and Biofeedback Therapy for Anorectal Disorders. Gut. 2016;7:A39A40.

8. Vasant D, Hamdy S, Solanki K, Senapati S, Smith L, Barlow J, Radhakrishnan N. PTU-122 A National Survey of GI Physiology \& Motility Services in The UK and Ireland. Gut. 2016;7:A116-A7. 
9. Stasinos I, Birdi S, Jayakumar S, Jayasundera J, Sattianayagam P. PWE428 Oesophageal ph/manometry - the trainees' perspective. Gut. 2015;64:A397-A8.

10. A journey toward excellence: training future gastroenterologists: The Gastroenterology Core Curriculum. Available at http://giorg/wp-content/ uploads/2011/07/fellows-GICoreCurriculumpdf 2007.

11. Sharma A, Leelasinjaroen P, Rao SS. Training in Neurogastroenterology and GI motility in USA: Preliminary Results of a Survey of Gastroenterology Fellowship Program Directors. Gastroenterology.150:S201.

12. Inaugral Issue. Digestive Matters, Georgia Regents Digestive Health Center. 2015.

13. Vasant DH, Xiang X, Amieva-Balmori M, Parr R, Sharma A, Rao SS. High Definition Anorectal Manometry Versus High Resolution Anorectal Manometry for Anorectal Disorders. Gastroenterology. 2017;152:S316.

14. Xiang X, Vasant DH, Amieva-Balmori M, Parr R, Sharma A, Rao SS. Sa1641Is there Diagnostic Gain or Loss with High Definition Versus High Resolution Anorectal Manometry. Gastroenterology. 2017;152:S316.

15. Vasant DH, Radhakrishnan NV. Competency based medical education in gastrointestinal motility-the UK perspective. Neurogastroenterol Motil. 2017;29. Epub 2016/12/29.

16. Carlson DA, Ravi K, Kahrilas PJ, Gyawali CP, Bredenoord AJ, Castell DO, Spechler SJ, Halland M, Kanuri N, Katzka DA, Leggett CL, Roman S, Saenz JB, Sayuk GS, Wong AC, Yadlapati R, Ciolino JD, Fox MR, Pandolfino JE. Diagnosis of Esophageal Motility Disorders: Esophageal Pressure Topography vs. Conventional Line Tracing. Am J Gastroenterol. 2015;110:967-77.

17. * Yadlapati R, Keswani RN, Pandolfino JE. Competency based medical education in gastrointestinal motility. Neurogastroenterol Motil. 2016. Epub 2016/04/12.

* This review paper is one of the first to define the need for competency based medical education in the field of GI motility diagnostics, and summarizes the potential of various approaches to addressing this need and how they may improve standard of care.

18. Yadlapati R, Keswani RN, Ciolino JD, Grande DP, Listernick ZI, Carlson DA, Castell DO, Dunbar KB, Gawron AJ, Gyawali CP, Katz PO, Katzka D, Lacy BE, Spechler SJ, Tatum R, Vela MF, Pandolfino JE. A System to Assess the 
Competency for Interpretation of Esophageal Manometry Identifies Variation in Learning Curves. Clin Gastroenterol Hepatol. 2016. Epub 2016/07/31.

19. Yadlapati R, Gawron AJ, Keswani RN, Bilimoria K, Castell DO, Dunbar KB, Gyawali CP, Jobe BA, Katz PO, Katzka DA, Lacy BE, Massey BT, Richter JE, Schnoll-Sussman F, Spechler SJ, Tatum R, Vela MF, Pandolfino JE. Identification of Quality Measures for Performance of and Interpretation of Data From Esophageal Manometry. Clin Gastroenterol Hepatol. 2016;14:526-34 e1. Epub 2015/10/27.

20. Yoon SS, Kuo B. Training in Gastrointestinal Motility. Dig Dis Sci. 2016;61:3105-7. Epub 2016/10/19.

21. Gaddam S, Reddy CA, Munigala S, Patel A, Kanuri N, Almaskeen S, Rude MK, Abdalla A, Gyawali CP. The learning curve for interpretation of oesophageal high-resolution manometry: a prospective interventional cohort study. Aliment Pharmacol Ther. 2017;45:291-9. Epub 2016/11/20.

22. * Yadlapati R, Keswani RN, Dunbar KB, Gawron AJ, Gyawali CP, Kahrilas PJ, Katz PO, Katzka D, Spechler SJ, Tatum R, Pandolfino JE. Benchmarks for the interpretation of esophageal high-resolution manometry. Neurogastroenterol Motil. 2016. Epub 2016/10/16.

* In a novel approach to GI motility training, the authors designed a high resolution manometry examination assessing competancy in 8 different interpretation skills, and used robust methodology to define competancy cut off scores for different levels of expertise.

23. Otaki F, Arora AS, Halland M. Correlation Between the Computer Generated High-resolution Esophageal Manometry Reports and Human Interpretation in the Diagnosis of Esophageal Motility Disorders. Gastroenterology.152:S332.

24. BSG. Care of Patients with Gastrointestinal Disorders in the United Kingdom A strategy for the future. 2006:28-9.

25. Collier. J, de Caestecker. J, J J. Gastroenterology: new subspecialties. BMJ Careers. 2007. 
Figure legends:

Figure 1: The number of motility procedures reported on by the motility fellow during the observed one-month period (total $n=302$ )

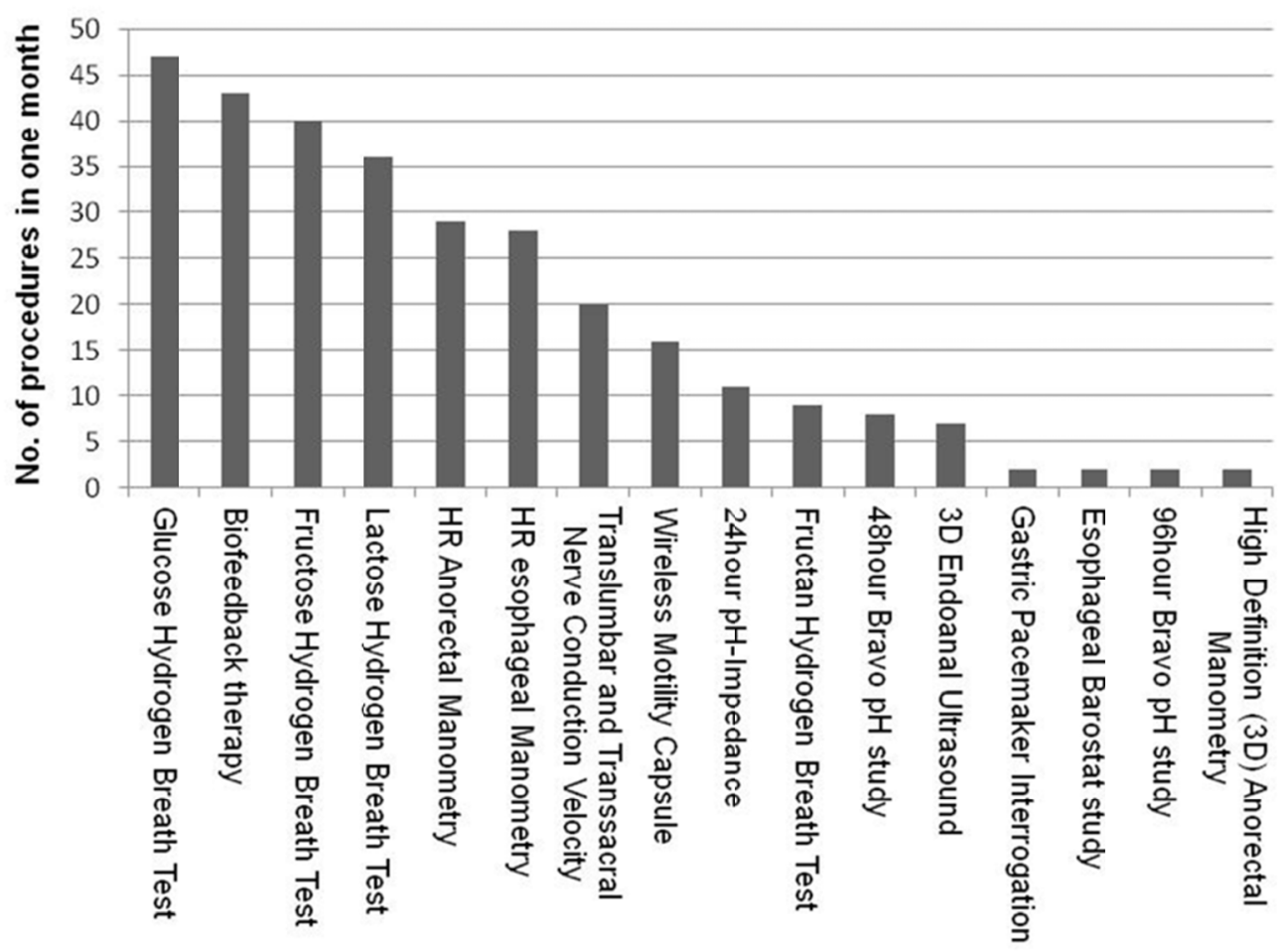


Figure 2: Trainees level of independence in the indications for motility tests posttraining

Indications for Motility tests $(n=12)$

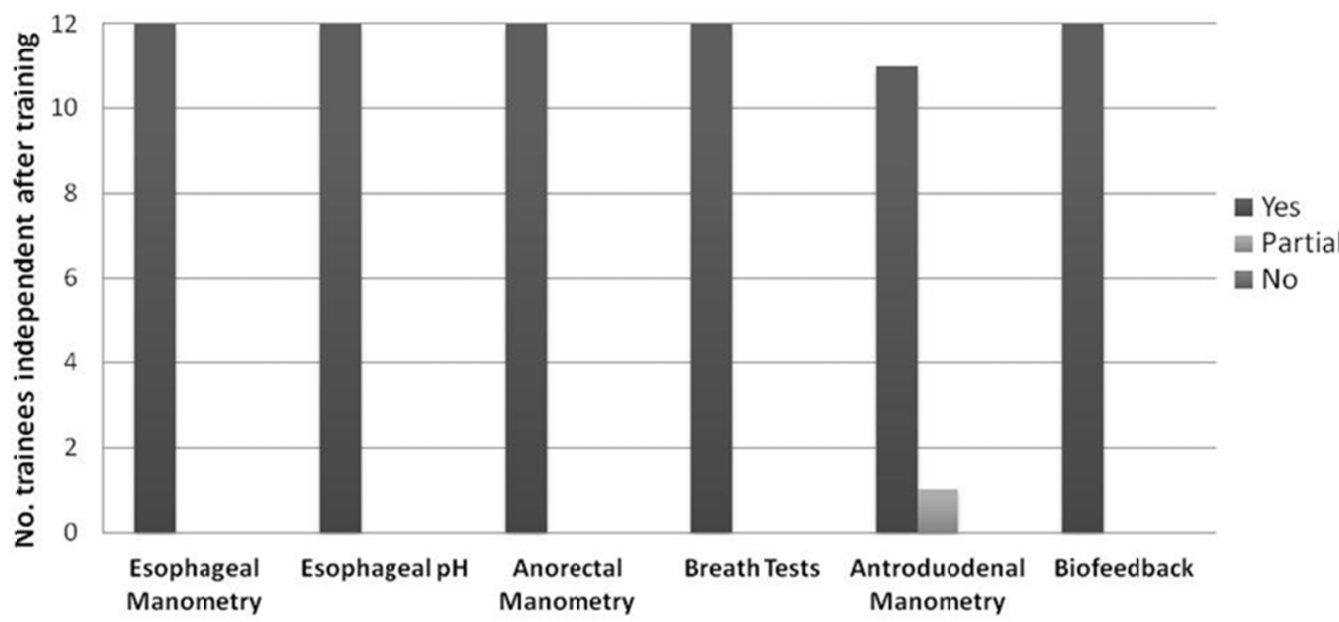

Figure 3: Trainees level of independence in the interpreting motility tests posttraining

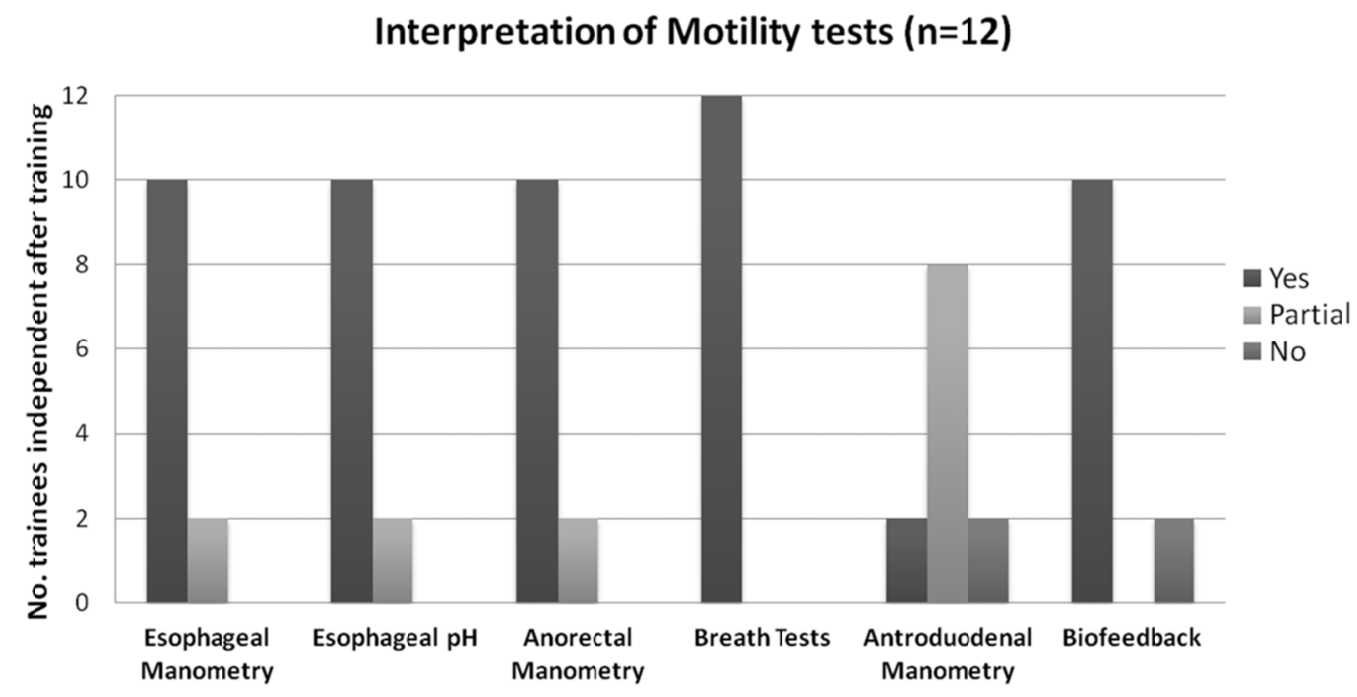


Figure 4: Trainees level of independence in performing motility studies post-training

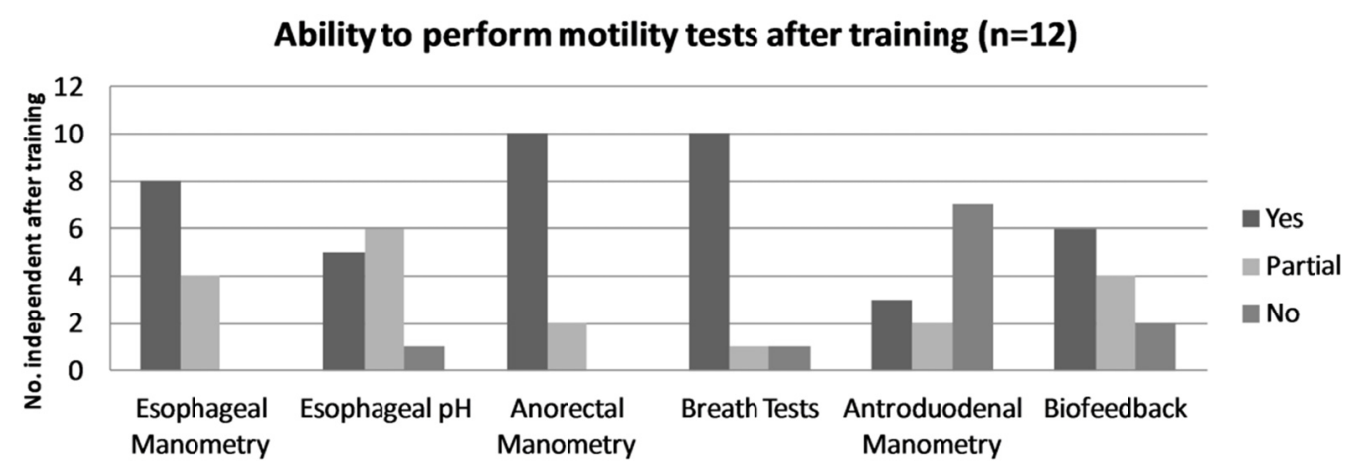

Figure 5: Performance on written test paper before and after apprenticeship-based NGM training

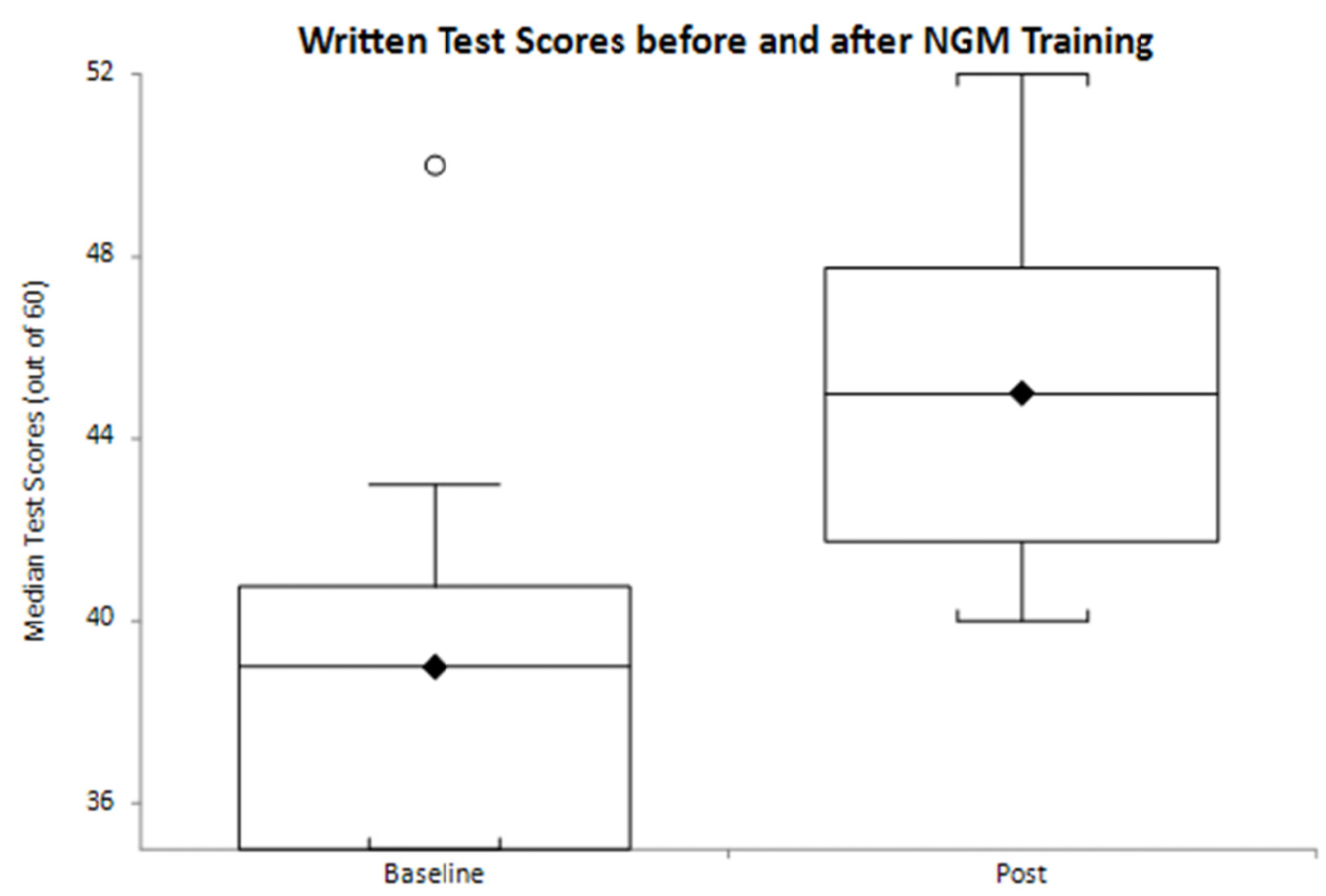


Table 1: Weekly timetable during apprenticeship-based training in NGM

\begin{tabular}{|c|c|c|c|c|}
\hline $\begin{array}{l}\text { Mo } \\
\text { nd } \\
\text { ay }\end{array}$ & $\begin{array}{l}8- \\
10 \text { am Motility clinic } \\
\text { s- } \\
\text { shadow Dr. Rao \& } \\
\text { Meet Dietician }\end{array}$ & $\begin{array}{l}10-12 \text { noon } \\
\text { Motility Lab, Observe pr } \\
\text { ocedures: esophageal } \mathrm{H} \\
\text { REPT, balloon distentio } \\
\mathrm{n}, \mathrm{pH} \text {, Breath test }\end{array}$ & $\begin{array}{l}1-4 \mathrm{pm} \\
\text { Anorectal Manometr } \\
\text { y \& Biofeedback An } \\
\text { d Translumbar NCV }\end{array}$ & $\begin{array}{l}4-5 \mathrm{pm} \\
\text { Data interpretation } \\
\text { Rounds \& didactic - } \\
\text { Dr. Sharma }\end{array}$ \\
\hline $\begin{array}{l}\text { Tu } \\
\text { es } \\
\text { da } \\
y\end{array}$ & $\begin{array}{l}7- \\
8 \text { am Problem/Core } \\
\text { Conference }\end{array}$ & $\begin{array}{l}8-12 \text { noon } \\
\text { Observe motility proced } \\
\text { ures }\end{array}$ & $\begin{array}{l}1-3 \mathrm{pm} \\
\text { Esophageal Balloon } \\
\text { distention \& Barostat } \\
\text { Studies/review vide } \\
\text { os }\end{array}$ & $\begin{array}{l}3-5 \mathrm{pm} \\
\text { Data interpretation } \\
\text { Rounds w/Dr.Rao }\end{array}$ \\
\hline $\begin{array}{l}\text { W } \\
\text { ed } \\
\text { ne } \\
\text { sd } \\
\text { ay }\end{array}$ & $\begin{array}{l}7- \\
8 \text { am Pathology/Ra } \\
\text { diology/ Motility/Int } \\
\text { erdisciplinary Confe } \\
\text { rence (didactic) }\end{array}$ & $\begin{array}{l}\text { 8-10 am } \\
\text { Motility Clinic - } \\
\text { shadow Dr. Sharma }\end{array}$ & $\begin{array}{l}10-12 \text { noon } \\
\text { Small bowel/colonic } \\
\text { Manometry - Dr. } \\
\text { Rao }\end{array}$ & $\begin{array}{l}1-4 \mathrm{pm} \\
\text { Observe procedures } \\
\text { in motility lab G } \\
\text { astric Barostat/biofe } \\
\text { edback/ Brain- } \\
\text { gut interaction } \\
4-5 \mathrm{pm} \text { Didactic Dr. } \\
\text { Sharma }\end{array}$ \\
\hline $\begin{array}{l}\text { Th } \\
\text { urs } \\
\text { da } \\
\text { y }\end{array}$ & $\begin{array}{l}8 \text { am - } \\
12 \text { noon Motility cli } \\
\text { nic (shadow Dr. Ra } \\
\text { o }\end{array}$ & & $\begin{array}{l}1-4 \mathrm{pm} \\
\text { Observe motility \& a } \\
\text { nal ultrasound \& eso } \\
\text { phogram defecogra } \\
\text { phy/scintigraphy }\end{array}$ & $\begin{array}{l}4-5 \text { pm } \\
\text { Data interpretation - } \\
\text { Rounds - Dr. Rao } \\
5-6 \text { pm } \\
\text { GI Fellows Researc } \\
\text { h Conference/Journ } \\
\text { al Club }\end{array}$ \\
\hline $\begin{array}{l}\text { Fri } \\
\text { da } \\
y\end{array}$ & $\begin{array}{l}\text { 7:30 - } \\
\text { 9:00 am Research } \\
\text { Lab meeting (option } \\
\text { al) }\end{array}$ & $9-10$ am Didactic & $\begin{array}{l}10-12 \text { noon } \\
\text { Motility lab procedur } \\
\text { es } \& \text { wrap- } \\
\text { up w/patients under } \\
\text { going weekly work- } \\
\text { up Gastric scintigra } \\
\text { phy and smartpill }\end{array}$ & $\begin{array}{l}1-3 \mathrm{pm} \\
\text { Review Motility vide } \\
\text { os/DVDs } \\
3-5 \mathrm{pm} \\
\text { Data Interpretation } \\
\text { Rounds - } \\
\text { Rao/Sharma }\end{array}$ \\
\hline
\end{tabular}


Table 2: Examples of cases and clinical problems observed in NGM teaching clinics

Assessment of patients with fecal incontinence including bedside clinical assessment for evidence of neuropathy

Approach to opiate induced constipation, narcotic bowel syndrome and centrally mediated abdominal pain syndromes

Assessment of chronic refractory constipation and clinical evaluation for pelvic floor dyssynergia

Investigation and management of dysphagia and esophageal dysmotility disorders including achalasia, esophago-gastric outflow obstruction and hypercontractility disorders.

Unexplained symptoms including gas/bloating, suspected small intestinal bacterial overgrowth and small intestinal fungal overgrowth

Investigation and management of suspected and confirmed Gastroparesis

Dysmotility in benign joint hypermobility syndrome

Dysmotility and malnutrition secondary to Scleroderma

Assessment of refractory Gastroesophageal reflux disease including patients with suspected extra-oesophageal reflux, the role of prolonged $\mathrm{pH}$ monitoring and oropharyngeal $\mathrm{pH}$ studies

Recurrent effortless vomiting and Rumination syndrome

Dysmotility following bariatric surgery

Chronic diarrhoea, post cholecystectomy biliary gastritis and bile salt malabsorption

Motility disorders secondary to neurological diseases including Parkinson's disease,

syringomyelia and transverse myelitis

Irritable Bowel Syndrome patients with constipation, diarrhoea and mixed sub-type

Psychological comorbidities in patients with functional gastrointestinal disorders

Assessments of patients with rectal pain with notable cases of levator ani syndrome, post-inflammatory rectal hypersensitivity in distal ulcerative colitis and solitary rectal ulcer syndrome.

Food intolerances including lactose, fructan and fructose

Functional dyspepsia and gastroparesis

Investigation and management of patients with symptoms of both upper and lower

motility disorders and the role of the wireless motility study. 